\title{
Балансирование интересов акционеров, кредиторов и бизнеса в разделительном и вступительном балансе при реорганизации компании
}

\author{
Евсеенков О.B. ${ }^{20}$
}

В статье рассмотрены организачионные и методические вопросы формирования разделительных и вступительных балансов при реорганизачии компании. Составление разделительного баланса должно отвечать нормативным ограничениям, интересам кредиторов, поставленным акиионерами задачам и требованиям устойчивости бизнеса. Это достигается распределением активов и обязательств по технологическому принципу и балансировкой дисконтированных денежных потоков по ликвидным активам и срочным обязательствам. Процедура контроля от даты, на которую составлен разделительный баланс, до фактической регистрации новых компаний и составления вступительного баланса должна обеспечить выполнение указанных требований в переходный период.

JEL: G34, M41

Ключевые слова: реорганизачия компании, разделительный баланс, вступительный баланс

Реорганизация компании в современном бизнесе является далеко не экстраординарным случаем. Часто компании вступают в альянсы, которые затем перерастают в юридическое объединение путем слияния, порой более сильные конкуренты поглощают и присоединяют слабых, растущие компании выделяют (spin off) в самостоятельные юридические лица отдельные бизнесы для большей гибкости в их развитии, огромные фирмы вынуждены разделяться вследствие требований антимонопольных органов или расхождения интересов основных акционеров. Современный финансовый кризис подталкивает ряд компаний к выделению отдельных активов или бизнесов для передачи в залог или продажи и погашения кредитного портфеля...

Если в случае слияния и присоединения финансовых вопросов относительно немного активы и обязательства всех компаний переходят к одному правопреемнику, который отвечает за всех, - то в случае разделения или выделения встает вопрос, как разделить активы и обязательства таким образом, чтобы созданные компании оказались финансово устойчивыми и имели достаточную ликвидность, а также как убедить в этом кредиторов (включая налоговые органы, которые в случае несогласия могут просто не зарегистрировать новые компании) и, возможно, миноритарных акционеров.

Структура активов и пассивов (как вновь образованных, так и реорганизованного общества) определяется тем, как будет сформирован и утвержден акционерами разделительный баланс. Не менее важно, каким образом будет сформирован баланс вступительный. Акционеры на общем собрании физически могут утвердить разделительный баланс только по состоянию на прошедшую дату, а с момента утверждения разделительного баланса до регистрации новых обществ должно пройти (для реализации предусмотренных законодательством процедур) не менее двух с половиной месяцев. Состояние активов и пассивов (в случае если общество не заморозило всякую деятельность за этот период, что для любой операционной компании практически невозможно) за этот период неизбежно изменится.

\footnotetext{
${ }^{20}$ Директор департамента казначейства и управления финансовыми рисками Государственной корпорации «Роснанотех».
} 
Таким образом, встает вопрос, как составить разделительный баланс, а также обеспечить соблюдение идей и принципов, заложенных в него, вплоть до момента формирования вступительного баланса новых обществ. С учетом опыта реорганизации дочерних обществ ОАО РАО «ЕЭС России» в 2004-2008 годах, в которой принимал участие автор, представляется целесообразным предложить следующие подходы.

Нормативной базой формирования разделительного баланса является Приказ Министерства финансов Российской Федерации № 44н от 20 мая 2003 года «Об утверждении методических указаний по формированию бухгалтерской отчетности при осуществлении реорганизации организаций».

Построение разделительного баланса при реорганизации путем выделения или разделения целесообразно осуществлять на основании подразумеваемого в базовом балансе денежного потока (положительного и отрицательного).

После реорганизации каждое из обществ должно иметь источники на покрытие кредиторской задолженности, адекватные тем средствам, которые имело реорганизуемое общество до реформирования. Такими источниками являются денежные средства, финансовые вложения, дебиторская задолженность, доходы от владения или реализации долгосрочных финансовых вложений, непрофильных активов. Распределение перечисленных активов - денежных средств, финансовых вложений, выданных займов, дебиторской задолженности, непрофильных активов, запасов, предназначенных для перепродажи, являющихся обеспечением исполнения обязательств, производится выделяемым и реорганизуемому обществу по их оценочной (а не балансовой) стоимости пропорционально распределенным обязательствам. Таким образом, во всех компаниях покрытие обязательств активами для их исполнения будет одинаковым.

Составление разделительного баланса проводится после проведения инвентаризации прав, обязательств, финансовых вложений, договоров и т.п. на основании инвентаризационных описей. При составлении разделительного баланса распределяются не только активы и пассивы, учтенные в базовом балансе, но и забалансовые обязательства и все договора. Предпочтительно, чтобы как можно скорее после принятия принципиального решения о реорганизации во всех договорах указывался правопреемник по данному договору.

Распределение внеоборотных активов и запасов осуществляется по технологическому принципу - в соответствии с характером и целями их использования в производственном процессе, кредиторской задолженности - в соответствии с местом и основанием ее возникновения.

Распределение по технологическому признаку означает, что основные средства распределяются таким образом, чтобы обеспечить выполнение выделяемым обществом своих производственных функций. Как правило, при этом объекты остаются на балансе того подразделения (филиала) компании, на основе которого создается выделяемое общество.

Механизмом, обеспечивающим возможность покрытия кредиторской задолженности, в той же степени, что и до реорганизации, является достижение равенства по всем обществам коэффициента баланса дисконтированных денежных потоков (далее - КДП), который рассчитывается как отношение приведенной стоимости положительного денежного потока, формируемого от перечисленных в предыдущем абзаце активов, к модулю приведенной стоимости отрицательного денежного потока на исполнение обязательств. Таким образом, будет достигнута равная платежеспособность всех обществ, образованных в результате реорганизации общества, включая само реорганизованное общество, и во всех из них каждый рубль обязательств будет обеспечен одинаковым количеством реальных активов.

Величины положительных и отрицательных денежных потоков, участвующих в расчете КДП, дисконтируются для получения приведенной стоимости согласно следующим принципам:

- приведенная стоимость элементов, формирующих положительный и отрицательный денежные потоки, рассчитывается отдельно по каждому виду активов и пассивов с применением соответствующих ставок дисконтирования: 
- дебиторская задолженность, а также финансовые вложения - по ставке $1 / 4$ от годовой средневзвешенной ставки, по которой кредитуется Общество, в квартал;

- кредиторская задолженность, НДС к уплате в бюджет - по ставке $1 / 4$ от годовой средневзвешенной ставки, по которой Общество размещает (или могло бы разместить) в квартал.

Период расчета приведенной стоимости (рассматриваемый период) представляется целесообразным принимать равным 3 годам (12 кварталам), начиная с даты составления разделительного баланса и исходя из предельного срока погашения кредиторской задолженности, после которого она может быть списана.

Приведенная стоимость дебиторской задолженности (если задолженность не является нереальной к взысканию, реструктурированной, мораторной или прочей) рассчитывается отдельно по каждому дебитору (группе мелких дебиторов одинакового вида задолженности, например население) с учетом динамики поступлений платежей от дебитора на протяжении 2 лет, предшествующих дате разделительного баланса.

Текущая дебиторская задолженность равна 1/24 стоимости продукции (работ, услуг), отпущенной за 2 года, предшествующие дате составления разделительного баланса, т.е. среднемесячному потреблению дебитора (если договорные отношения с дебитором составляют менее 2 лет, расчет составляется исходя из фактического срока взаимоотношений). Просроченная дебиторская задолженность определяется как разность между остатком дебиторской задолженности на конец периода (дату разделительного баланса) и текущей дебиторской задолженностью.

Оплата в каждом квартале для просроченной дебиторской задолженности рассчитывается как средняя оплата просроченной задолженности за предыдущие 2 года. Для этого за 2 года, предшествующие дате составления разделительного баланса, рассчитывается срок оплаты просроченной дебиторской задолженности.

График гашения реструктурированной дебиторской задолженности определяется исходя из заключенных соглашений о реструктуризации, мировых соглашений.

График гашения мораторной дебиторской задолженности определяется исходя из сроков окончания моратория.

Нереальная к взысканию дебиторская задолженность принимается к расчету приведенной стоимости по нулевой стоимости.

Приведенная стоимость просроченной дебиторской задолженности рассчитывается как сумма приведенных стоимостей всех платежей в погашение задолженности, осуществляемых в каждом периоде (квартале). Квартальные потоки в каждый год рассматриваемого периода равны $1 / 4$ годового потока.

Кредиторская задолженность делится на следующие виды:

- неделимая;

- делимая.

К неделимой кредиторской задолженности относится задолженность перед бюджетом и внебюджетными фондами (за исключением НДС в дебиторской задолженности). Она не распределяется и остается на реорганизуемом обществе.

К делимой кредиторской задолженности относится кредиторская задолженность, не отнесенная к неделимой, в том числе задолженность поставщикам и подрядчикам, полученные авансы, прочая кредиторская задолженность, по которой, в соответствии с требованиями законодательства, может быть установлен иной правопреемник

При этом следует идентифицировать договоры займа, содержащие ограничивающие условия (например, займы, выданные под залог объектов основных средств). Такие займы относятся к неотделяемой от соответствующего актива кредиторской задолженности, так как должны быть распределены вместе с соответствующими активами.

Отрицательный денежный поток рассчитывается как сумма текущей кредиторской задолженности, дисконтированной стоимости урегулированной кредиторской задолженности и дисконтированных выплат основной суммы и процентов по займам и кредитам. 
Стоимость текущей кредиторской задолженности принимается к расчету по балансовой стоимости.

Приведенная стоимость урегулированной кредиторской задолженности и займов рассчитывается как сумма приведенных стоимостей платежей в погашение задолженности и процентных платежей, осуществляемых в каждом расчетном периоде (квартале) согласно имеющимся графикам платежей и исходя из 3-летного максимального срока погашения.

Кредиторская задолженность, погашение кредитов, займов и процентные платежи, проводимые более чем через 3 года после даты реструктуризации, принимаются к расчету как кредиторская задолженность, погашаемая в последнем (12-м) расчетном периоде (квартале).

Краткосрочные и долгосрочные кредиты и займы распределяются аналогично активам, на приобретение которых они использовались.

Денежные средства по реорганизуемому и выделяемым обществам распределяются пропорционально величине их отрицательного денежного потока. Покрытие отрицательных денежных потоков денежными средствами должно быть приблизительно равным по реорганизуемому и выделяемым обществам.

В случае если значение коэффициента баланса денежных потоков (КДП) по какомулибо из выделяемых обществ и реорганизуемому обществу более чем на 5\% отличается от коэффициента баланса денежных потоков (КДП) по любому другому из выделяемых обществ и реорганизуемому обществу или от дореформенного КДП, необходимо произвести перераспределение дебиторской задолженности, а если такого «выравнивания» недостаточно, то делимой кредиторской задолженности.

Собственный капитал распределяется таким образом, чтобы сохранить балансовое равенство по всем выделяемым компаниям, при этом необходимо стараться выравнять отношение чистый активов к собственному и особенно уставному капиталу в целях обеспечения «запаса» от снижения чистых активов в начале функционирования новых компаний ниже уставного капитала, что через некоторое время может привести к необходимости снижения уставного капитала.

Порядок распределения дебиторской и кредиторской задолженности, возникшей в период, переходный от даты составления разделительного баланса до даты государственной регистрации выделяемых обществ (а по сути, от распределения доходов и расходов в этот период), должен быть описан в Правилах правопреемства, утверждаемых собранием акционеров одновременно с разделительным балансом. Описание этого порядка довольно сложное, поскольку все-таки возникающая дебиторская и кредиторская задолженность (понятия, которыми оперирует баланс как отчетность на дату) нетождественна доходам и расходам (которые возникают в период между датами разделительного и вступительного баланса). Например, во многих компаниях существует проблема «перекрестной амортизации», когда бухгалтерская амортизация начисляется по одним видам деятельности, а денежные средства расходуются на инвестиции в основные фонды других видов деятельности. Кроме того, часть кредиторской задолженности является неделимой (налоги, заработная плата) и должна быть отнесена на реорганизуемое общество, а соответствующие расходы осуществляются по другим видам деятельности (подобное происходит, например, с заработной платой). Автор предлагает следующий подход к этому описанию.

В случае, если кредиторская или дебиторская задолженность возникает в переходный период, а обязательство (на основании договора, иного правового основания), в результате которого сложилась данная кредиторская или дебиторская задолженность, возникло ранее даты составления разделительного баланса, то такая кредиторская или дебиторская задолженность должна быть отнесена к реорганизуемому или к тому выделяемому обществу, которому было отнесено данное обязательство в соответствии с разделительным балансом.

При возникновении в переходный период обязательства и, соответственно, кредиторской и дебиторской задолженности необходимо определить ее целевое назначение 
для осуществления видов деятельности, после чего такая кредиторская или дебиторская задолженность должна быть отнесена к соответствующей компании.

В случае исполнения контрагентом обязательств, возникших в переходный период, денежные средства (эквиваленты денежных средств при неденежных формах расчетов), вырученные реорганизуемым обществом в результате такого исполнения, должны быть отнесены к реорганизуемому или выделяемым обществам - в зависимости от того, к какому обществу была отнесена соответствующая дебиторская задолженность в соответствии с двумя вышестоящими абзацами, за исключением следующих особенностей.

1. Сумма денежных средств (их эквивалентов), подлежащая распределению, увеличивается на сумму дебиторской задолженности, возникшей, но не оплаченной в переходный период. При этом на указанную сумму уменьшается сумма денежных средств, подлежащая распределению реорганизуемому или выделяемому обществу, к которому относится данная задолженность (поскольку ему достанется дебиторская задолженность, которая затем будет обращена в денежные средства).

2. Денежные средства (эквиваленты денежных средств) в сумме чистой прибыли (убытка), полученной в переходный период, относятся на реорганизуемое общество (поскольку из этих средств реорганизуемое общество будет выплачивать дивиденды), за исключением случаев, когда в специально формируемом приложении «Инвестпрограмма» прямо указано, что прибыль полностью или частично является источником финансирования предусмотренных приложением «Инвестпрограмма» расходов выделяемого общества. В этом случае реорганизуемому обществу распределяется оставшаяся часть прибыли (за минусом указанной в приложении «Инвестпрограмма»).

Этот пункт обеспечивает денежными средствами реорганизуемое и выделяемое общества исходя из планируемой величины выплаты дивидендов и финансирования инвестиционной программы за счет чистой прибыли.

3. Денежные средства (их эквиваленты) распределяются между реорганизуемым и выделяемым обществами в сумме затрат, относящихся к каждому виду деятельности. При этом под затратами понимаются расходы, включаемые в состав себестоимости, управленческих и коммерческих расходов, прочих расходов, процентов, уплачиваемых по кредитам и займам, а также обязательных платежей с учетом следующих особенностей:

3.1. Расходы по выкупу акций относятся к затратам реорганизуемого общества.

3.2. Выплаты пенсионерам, ушедшим на пенсию из реорганизуемого общества, относятся к затратам реорганизуемого общества.

3.3. В состав затрат не включается списание безнадежной дебиторской задолженности.

3.4. Расходы по уплате налога на прибыль относятся к реорганизуемому обществу.

3.5. В состав затрат не включаются амортизационные отчисления.

Данный пункт обеспечивает денежными средствами финансирование текущих затрат реорганизуемого и выделяемого обществ с учетом их денежного характера (неденежные «затраты» по списанию дебиторской задолженности и амортизации основных фондов не учитываются) и требований законодательства по сохранению кредиторской задолженности по налогам и выплатам персоналу на реорганизуемом обществе.

4. Размер денежных средств, распределяемых каждому выделяемому обществу, уменьшается на сумму неисполненных налоговых обязательств, относящихся к деятельности данного общества и не передаваемых в порядке правопреемства в данное общество, с соответствующим увеличением денежных средств, распределяемых реорганизуемому обществу - поскольку кредиторская задолженность по налогам является неделимой и полностью относится на реорганизуемое общество.

5. Из оставшейся после выполнения пунктов 1-4 суммы денежных средств (их эквивалентов) реорганизуемому или соответствующему выделяемому обществу распределяются денежные средства (их эквиваленты) в сумме капитальных вложений, предусмотренных в приложении «Инвестпрограмма». В случае если оставшаяся сумма денежных средств (их эквивалентов) меньше суммы, предусмотренной в приложении 
«Инвестпрограмма», отнесение денежных средств (их эквивалентов) производится пропорционально суммам, указанным в инвестиционной программе.

Этот пункт предусматривает распределение денежных средств, направляемых на финансирование инвестпрограммы за счет чистой прибыли. Поскольку наверняка не известно, в какую именно дату состоится регистрация выделяемых обществ, инвестпрограмма описывается на срок «с запасом» по отношению к планируемой дате регистрации. Если фактическая прибыль оказывается меньше запланированной для использования на инвестиции, денежные средства на их финансирование уменьшаются пропорционально по всем компаниям.

6. Оставшаяся после выполнения пунктов 2-5 сумма денежных средств (их эквивалентов) относится к реорганизуемому или соответствующему выделяемому обществу пропорционально размеру амортизационных отчислений, относящихся к реорганизуемому или соответствующему выделяемому обществу.

Для контроля результатов переходного периода, выполнения Правил правопреемства и обеспечения финансовой устойчивости реорганизуемых обществ до государственной регистрации выделенных обществ целесообразно составить «промежуточный» разделительный баланс. «Промежуточный» разделительный баланс - баланс (форма 1) по реорганизуемому и выделяемым обществам, составленный на любую дату переходного периода, т.е. фактически отчет об уже произошедших изменениях к разделительному балансу. Одновременно можно сформировать контрольные показатели вступительных балансов. Контрольные показатели вступительных балансов - это набор показателей, рассчитываемых на основании «прогнозных» балансов по реорганизуемому и выделяемым обществам на дату государственной регистрации выделяемых обществ. Для корректного расчета контрольных показателей необходимо осуществить прогноз финансовохозяйственной деятельности в разрезе реорганизуемого и выделяемых обществ с даты, по состоянию на которую составляется «промежуточный» разделительный баланс, по дату государственной регистрации выделенных обществ (необходимо составление бюджета движения денежных средств, прогнозного отчета о прибылях и убытках, баланса по всем создаваемым компаниям).

Этот промежуточный вступительный баланс поможет акционерам и менеджменту понять, насколько выдержаны принципы разделительного баланса и требования правил правопреемства, принять решение о готовности к государственной регистрации обществ, дать базу для оценки деятельности генерального директора по проведению реорганизации.

Вступительный баланс формируется на основании передаточных актов от реорганизуемого общества ко вновь созданным. Эти акты составляются на основании разделительного баланса с учетом правил правопреемства и должны проверяться представителями соответствующих компаний; акционеры реорганизованной компании должны оценить соответствие фактического вступительного баланса промежуточному и принять соответствующие управленческие меры (премирование, увольнение).

Реализация данных процедур должна обеспечить формирование в результате реорганизации финансово и экономически устойчивых (по крайней мере, относительно реорганизуемой) новых компаний. 